\title{
Desvestindo A noiva de Frankenstein
}

José Cattil

I José Gatti é professor na Universidade Federal de Santa Catarina, na Universidade Tuiuti do Paraná e no Centro Universitário Senac/SP. Tem livros e artigos publicados sobre políticas de representação nos meios audiovisuais. Organizador, com Fernando Marques Penteado, do livro Masculinidades: teoria, crítica e artes (Estação das Letras e Cores, 2011).E-mail:zegatti@uol.com.br 


\section{Resumo}

Este trabalho busca definir e identificar elementos de subversão cronotópica no cinema. Para essa tarefa, serão utilizados conceitos propostos por Mikhail Bakhtin, Lezama Lima e Ismail Xavier numa análise textual de A noiva de Frankenstein (James Whale, 1935).

\section{Palavras-chave}

Cinema de horror, direção de arte, políticas de representação, subversão cronotópica.

\section{Abstract}

This essay seeks to define and identify elements of chronotopic subversion in film. For that task, concepts proposed by Mikhail Bakhtin, Lezama Lima and Ismail Xavier will be used in a textual analysis of The bride of Frankenstein (James Whale, 1935).

\section{Keywords}

Horror film, art direction, politics of representation, chronotopic subversion. 
ano 2 número 4

O conhecimento se traduz no nomear: ao recortarmos o real e darmos nomes às partes, acreditamos conhecer a verdade e estabelecemos uma relação entre a palavra e o recorte.

Julio Jeha

Este é um exercício de análise textual que faz par te de um projeto de pesquisa, em que examino cronotopos no cinema. Para essa tarefa, tomo aqui como exemplo A noiva de Frankenstein (James Whale, 1935), filme que se tornaria cultuado nos anos subsequentes a sua realização, fazendo hoje parte do cânone dos compêndios de história do cinema. O filme dá continuidade à história contada em Frankenstein, dirigido pelo próprio Whale em 1931 e adaptação do romance Frankenstein ou o moderno Prometeu de Mary Wollstonecraft Shelley, publicado em 1818. É, portanto um filme produzido pela indústria (no caso, Universal Studios) e destinado a um amplo público, mas que também estabelece um diálogo com a chamada alta literatura. Além disso, trata-se de um caso especial, que nos permite abordá-lo como um filme de subversão cronotópica, pois, como veremos, a narrativa de A noiva de Frankenstein está pontuada por indícios de tempos e espaços discrepantes e que convivem nas mesmas cenas.

Por outro lado, esse é um filme que, ao longo dos anos, passou por muitas transformações. Explico melhor: ofilme propriamente dito podeestar preservado, mas a maneira como é recebido/percebido varia de acordo com seu momento de exibição. Em outras palavras: a espectatorialidade sofreu transformações e, nessa perspectiva, o filme veio a ser apreciado de distintas formas. Desse modo, na contemporaneidade, podemos apreciar elementos cronotópicos de $A$ noiva de Frankenstein que talvez não estivessem disponíveis para o público de 1935. Aparentemente não estavam para a crítica contemporânea do filme, que não deixou registros sobre a questão.

Eventuais descontinuidades espaço-temporais não parecem ter causado prejuízo em sua reputação como filme de horror. Se hoje nós o percebemos como um filme de terror é porque o mundo mudou, o cinema mudou e, com eles, a maneira de percebermos os filmes. Esses elementos, que hoje podem ser entendidos como 
parte de uma narrativa que entabula um diálogo lúdico, não o eram em 1935, quando o filme foi lançado. Até mesmo o atrevido (e divertido) apelo do cartaz original, "Warning! The Monster demands a Mate!"2, cheio de insinuação sexual numa época em que a produção cinematográfica era rigidamente controlada pelo Código Hays de censura, servia para alimentar o sentimento de atração, horror e repulsa que caracterizam o gênero. Assim, pode-se supor que eventuais discrepâncias espaço-temporais da narrativa de A noiva de Frankenstein passaram despercebidas pelo público, chocado demais para notá-las.

Podemos avaliar um pouco do impacto do cinema de Whale no filme $O$ espírito da colmeia, realizado por Victor Erice em 1973. O filme retrata a exibição de Frankenstein numa pequena comunidade do interior da Espanha, por volta de 1940. As protagonistas, duas meninas em idade escolar, se aterrorizam com o personagem da tela, até o momento em que entram em contato com outro "monstro", um guerrilheiro perseguido pelas tropas fascistas, escondido numa tapera abandonada. Esse encontro, que desencadeia a iniciação das meninas à vida adulta, exigirá delas a redefinição do que se considera um monstro. Mas o que importa aqui é que, no contexto diegético de $O$ espírito da colmeia (isto é, a Espanha franquista pós-Guerra Civil), Frankenstein ainda mantém suas qualidades de filme aterrorizante.

Além disso, vale a pena lembrar que a obra de Whale é abordada, neste estudo, como filme de terror de narrativa realista, isto é: se houver um cientista capaz de criar monstros, o filme o mostra de forma plausível, pelo menos para o público dos anos 1930 e 1940. Seja baseado em episódios históricos ou não, o filme de horror é, portanto, realista - mesmo que sua narrativa seja habitada por monstros improváveis.

\section{Subversão cronotópica}

Elementos de subversão cronotópica podem, com efeitos variáveis, apontar para diferentes formas de representação do mundo, suscitando diferentes posicionalidades espectatoriais. Isto é: parto da hipótese de que as audiências 
ano 2 número 4

Temáticas

Livres

podem ser solicitadas a se posicionarem de formas diferentes diante de modos de representação diferentes.

O estilo narrativo hegemônico no cinema mantem sua base em formatos de representação realista, alicerçados por regras de continuidade estabelecidas desde o início do século XX. Essas regras têm fortes raízes históricas no cinema de narrativa clássica e muitos elementos característicos desse período formativo permanecem vigentes na produção contemporânea. Essa prática cinematográfica, ainda dominante, foi responsável pela formação espectatorial dos meios audiovisuais desde a segunda década do século XX, e fez também com que o público visse nessa forma de representação uma qualidade intrínseca ao próprio meio, deixando todas as outras formas de representação relegadas a categorias específicas (como, por exemplo, a do cinema experimental) ou, ainda mais grave, na categoria de equívoco ou erro, num processo de desqualificação de filmes que não se enquadrariam nas regras de continuidade (como os filmes de baixo orçamento, por exemplo).

Essa postura persiste vigorosa no meio cinematográfico, podendo ser facilmente detectada, por exemplo, nos currículos de certas escolas e nos "manuais de roteiro" que abundam nas prateleiras das livrarias, no Brasil e em outros países. O resultado é que, para o senso comum, filmes são feitos para se mostrar um mundo que se imagina imbuído de continuidade e causalidade lógica e, por esse princípio, gerações de roteiristas são formadas dentro desse paradigma de imenso poder ideológico.

O trabalho de Mikhail Bakhtin (1981) pode nos ajudar a compreender como esse paradigma se impõe. O autor russo desenvolve o conceito de cronotopo, para designar as relações espaço-temporais que estão no cerne da estrutura narrativa do romance - e, por extensão, também do cinema. O cronotopo se manifesta de forma concreta, por exemplo através de indicadores geográficos e temporais, delineando desse modo a marca também concreta — da narrativa em nosso imaginário.

Também recorro aqui às categorias formuladas por Ismail Xavier em seu livro O discurso cinematográfico. Nesse trabalho Xavier apresenta dois atributos: opacidade e transparência. Nem sempre excludentes, esses atributos servem 
para se abordar as diferenças entre um cinema de continuidade e suspensão da descrença, ou seja, de transparência, e um outro cinema, de opacidade, que exige uma participação ativa por parte do espectador e se coloca, dessa forma, como alternativa ao cinema hegemônico.

Podemos, também, agrupar filmes em dois campos distintos: filmes de narrativa transparente e subversão cronotópica involuntária, e filmes de narrativa opaca, ou de subversão cronotópica deliberada. No primeiro grupo se alinhariam os filmes que apresentam elementos de subversão sem um projeto de produzir uma perspectiva crítica por parte do público - como, por exemplo, os filmes "desqualificados", mencionados acima. Nesse campo podemos reunir toda uma linhagem de filmes produzidos pela indústria do entretenimento e que, em maior ou menor medida, não logram manter congruências de continuidade e verossimilhança. Por outro lado, podem ser incluídos, neste grupo, muitos filmes com chancelas de "qualidade", que retratam períodos históricos determinados num ponto específico do passado, conhecidos em inglês como period films. Incluem-se aí as séries bíblicas, o gênero western, e mesmo filmes do gênero horror. É visível, nesses filmes, o esforço de seguir certos parâmetros de figurino e cenário que sejam coerentes com a imagem que o público já tem de um determinado período histórico - e diretores de arte frequentemente apoiam seus trabalhos em pesquisas iconográficas e literárias. No entanto, é sabido que esses filmes evidenciam, também, diretivas próprias do sistema de estrelas, que exige a manutenção de quesitos relacionados à imagem dos elencos. Isso se nota, por exemplo, na frequente discrepância entre a maquiagem e os penteados contemporâneos ao momento da produção e os figurinos pesquisados em documentos históricos, criando figuras híbridas em termos cronotópicos.

O problema se coloca na medida em que o cronotopo se constitui apenas para (re)afirmar parâmetros de um realismo delimitado ideologicamente, como pratica o cinema hegemônico. Podemos identificar obras que desafiam esses parâmetros, apresentando elementos de subversão cronotópica - isto é, que subvertem cronotopos ajustados à expectativa limitada pelo entendimento do cinema como veículo destinado à produção de textos realistas. Nos últimos anos, diversos filmes têm aplicado estratégias narrativas que deliberadamente 
ano 2 número 4

Temáticas

Livres

subvertem regras de continuidade e linearidade diegética, isto é, a articulação dominante entre códigos de linguagem audiovisual presentes em fórmulas consagradas de caráter realista. Essas narrativas, ao irromperem em filmes aparentemente ajustados em convenções previsíveis, apresentam elementos que sugerem a-temporalidades ou trans-temporalidades e, desse modo, solicitam novas posturas espectatoriais. Refiro-me aqui a filmes que desrespeitam normas convencionais de diegese, apresentando figurinos, trilha sonora, cenários e objetos que estabelecem tempos e espaços em descompasso. Esses filmes parecem convidar seus espectadores a entrarem num diálogo que desafia a suspensão da descrença — outra regra básica estabelecida pelo cinema clássico. Assim como a continuidade, a suspensão da descrença é um procedimento que informa a espectatorialidade cinematográfica, expressa numa espécie de pacto, permitindo que o público supere objeções que poderiam se constituir pela não aceitação de inverossimilhanças na narrativa. Estão entre esses filmes os experimentos radicais de Derek Jarman, como Sebastiane (1976), Caravaggio (1986) e Eduardo II (1991); e também de Alex Cox, cuja obra Walker (1987) encena uma Nicarágua que mescla, simultaneamente, 1855 e 1985. Vale assinalar também o recente Maria Antonieta (Sofia Coppola, 2006), de grande alcance comercial, que, além de acoplar som de rock a passos de minueto, ousou introduzir um conspícuo par de tênis All star na coleção de sapatos ancien régime da rainha. Desse modo, filmes como esses parecem abrir espaço para leituras que valorizam qualidades metafóricas que passam a ocupar papel proeminente, a ponto de superarem as costumeiras armadilhas textuais desencadeadas por prerrogativas genéricas pré-estabelecidas.

Nesse processo de subversão, os cronotopos podem ser reorganizados de modo a criarem novos arcos significativos sobre tempos e espaços, para produzir aquilo que Lezama Lima denominou Eras imaginárias. Elas se expressam em narrativas nas quais elementos de épocas diferentes erigem um arco espaço-temporal capaz de produzir significados indetectáveis nos relatos de continuidade (e aqui estendo o conceito de continuidade narrativa àquela mesma continuidade da técnica cinematográfica, pedra fundamental do cinema hegemônico, sustentáculo da quarta parede e condição sine qua non 
para a manutenção da suspensão da descrença que rege as espectatorialidades convencionais). Diz Lezama: “Los nexos causales en un continuo parecen como um reto al azar, a los sortilegios". (1971, 372) É esse azar, esse acaso, que alimenta o texto poético, que abre portas para os espectadores que encontrarão seus próprios caminhos de leitura.

Produzido num contexto em que se privilegiava o cinema de transparência, $A$ noiva de Frankenstein parece irromper com elementos de opacidade e subversão cronotópica - e parece capaz, também, de erigir seus próprios arcos espaçotemporais significativos. É o que tentarei examinar em seguida.

\section{palacete da escritora}

Partindo dessa premissa, como se constrói a diegese de A noiva de Frankenstein? O filme abre com cenas no salão de um palacete. Ali estão reunidos Mary Shelley, a autora do romance Frankenstein (vivida pela atriz Elsa Lanchester), seu marido, o poeta Percy Shelley (Douglas Walton) e o grande amigo do casal, o poeta-aventureiro George Byron (Gavin Gordon). Apesar de não haver indicações na tela, sabemos que o palacete estava localizado na Suíça, e que foi efetivamente compartilhado pelos três no verão de 1816. Os créditos de abertura já haviam anunciado: "Suggested by the original story written in 1816 by Mary Wollstonecraft Shelley and adapted by William Hurlbut - John Balderston". ${ }^{3}$ Desse modo, Whale dialoga com vários tipos de público, inclusive aquele que detém um conhecimento das biografias daqueles personagens. Para um público mais amplo, bastará identificar ali os personagens (que se nomeiam mutuamente nos diálogos), sua posicionalidade social (pertencem à elite) e temporal (o início do século XIX).

Naquele salão, quase tudo remete àquela época - o figurino, os objetos de cena e a arquitetura classicista, de pé direito descomunal. A direção de arte do filme é assinada por Charles D. Hall, que nessa cena mantém

3. "Inspirado na estória original escrita em 1816 por Mary Wollstonecraft Shelley e adaptada por William Hurlbut - John Balderston”. 
ano 2 número 4

Temáticas

Livres

padrões cuidadosos de continuidade e autenticidade. Esses padrões podem ser identificados até mesmo nos sotaques dos personagens: em meio aos floreados elogios que faz ao talento de Mary, Lord Byron auto-ref lexivamente refere-se a seu próprio falar impostado, possivelmente de inflexão escocesa ("I even r-r-roll my Rs as I speak..."4).

Trata-se, portanto, de uma visão (de 1935) de como aquele momento (Suíça, 1816) deveria ser representado, de acordo com convenções de verossimilhança e realismo, isto é, de como se imaginava que os personagens se vestissem e falassem. A abertura de A noiva de Frankenstein cumpre, assim, diversas funções: certifica a narrativa com a autenticidade expressa pela própria voz autoral de Mary e encobre, desse modo, a voz autoral de James Whale e seus colaboradores (que incluíam, tanto no elenco quanto na área técnica, um grande número de britânicos como Whale) no estúdio Universal em Hollywood. Além disso, confere à narrativa fílmica um status de alta arte que a literatura escrita poderia atribuir - lembremos que o cinema, no momento em que Frankenstein foi realizado, dificilmente era visto como uma manifestação cultural de prestígio.

Lá fora, o palacete é castigado por uma tempestade de raios e trovões; no salão, Mary faz um bordado, ladeada por Shelley e Byron. Nessa cena, Lanchester usa um vestido de gaze branca, com lantejoulas formando borboletas, estrelas e luas, compondo um clichê quintessencial de feminilidade.

Ao ferir-se com uma agulha, ela é socorrida pelos dois homens, que se espantam com o fato de uma criatura tão frágil ter sido capaz de escrever uma história de tamanha brutalidade como Frankenstein. (Figura 1) Ao que Mary, instada por Byron, resolve dar continuidade à história de Frankenstein e seu monstro. A fragilidade de Mary parece assegurar ao espectador imbuído de espírito patriarcal que sim, a mulher já tem um lugar definido. No entanto, a ambiguidade parece prevalecer, pois essa mesma mulher frágil assumirá o comando da aterrorizante narrativa.

4. "Eu até enr-rolo meus er-res, enquanto falo..." 


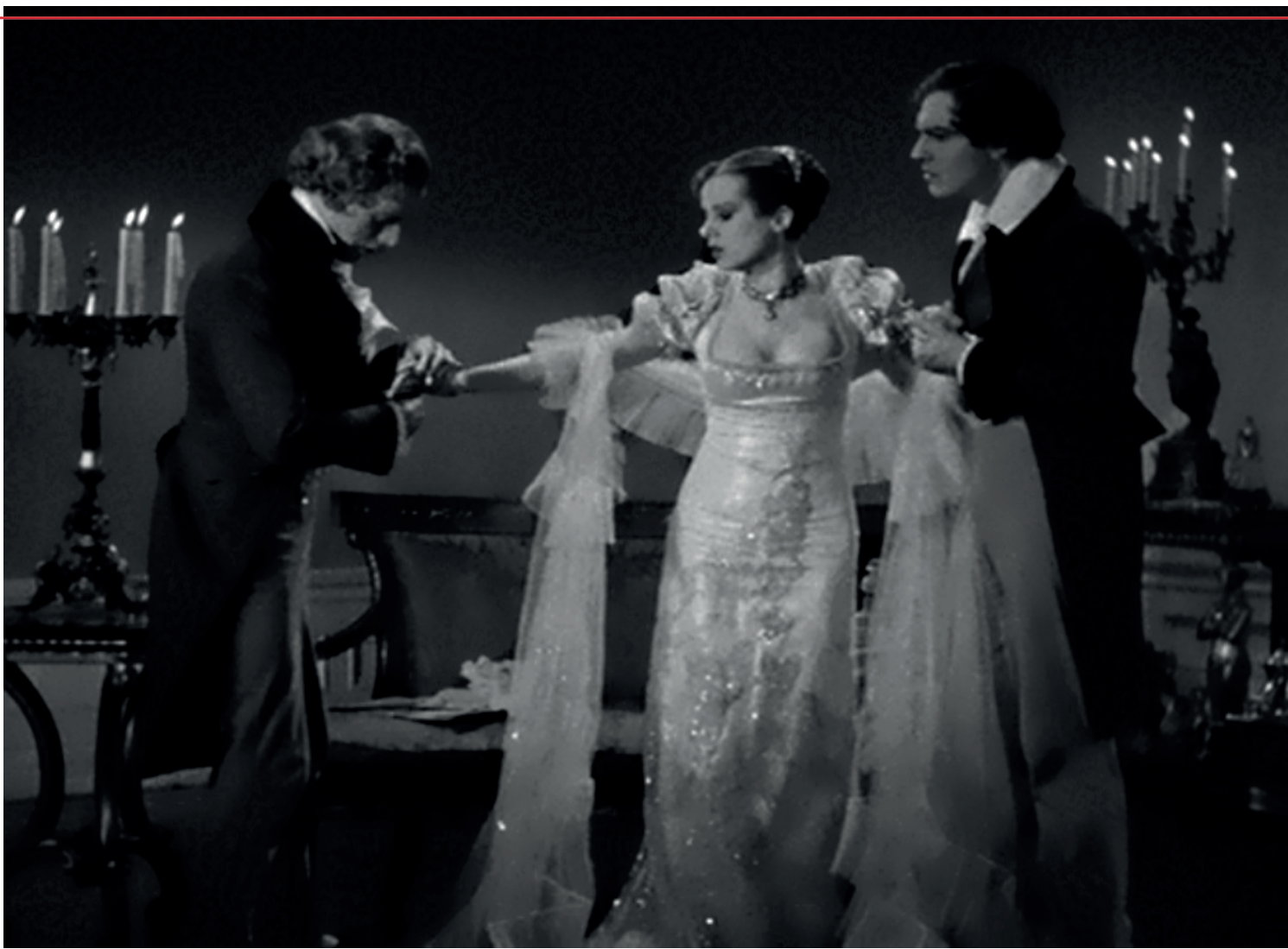

Figura 1

Byron diz "I am all ears!"5, e Mary começa a narrar. E com essa estratégia de caráter auto-reflexivo, o filme indica aos espectadores que a cena de 1816 é apenas uma introdução à história principal.

\section{mundo do monstro}

Passamos, portanto, de um cronotopo preciso, um salão na Europa do início do século XIX, para outro contexto cronotópico: o mundo ficcional criado pela personagem-autora Mary Wollstonecraft Shelley. A voz over da narradora entra em fade e a tela é ocupada pelo novo contexto diegético, pois, a partir desse momento, veremos as cenas dessa outra história. No entanto, o que Mary conta a seu marido, a Byron e, por extensão, a nós espectadores, é representada em falas, cenários, objetos de cena e figurinos que resultam numa articulação de tempos e espaços distintos daqueles que denotavam a Suíça de 1816. De certa 
ano 2 número 4

Temáticas

Livres forma, Mary monta sua história a partir de partes de outros cronotopos, criando um corpo novo e complexo, quiçá monstruoso. Daí a tarefa deste estudo: a de tentar recortar o real fílmico e dar nome às partes que o constituem, ciente de que essa busca esteja baseada na mera presunção de se conhecer a verdade que ele porventura encerra.

Onde acontece a história? A trama supostamente acontece em algum lugar da Europa central, com a predominância de nomes alemães. Os habitantes da aldeia assolada pelo monstro se apresentam ora como camponeses centroeuropeus, a falar inglês com sotaques, ora vagamente germânicos, ora vagamente britânicos (um arremedo inglês britânico era muito valorizado em Hollywood naquele momento), ou claramente irlandês (caso de Minnie, camareira do castelo de Frankenstein, personagem vivida pela célebre comediante irlandesa Una O'Connor). O prefeito da cidade é chamado de Burgomaster, um termo inglês de notória ressonância germânica.

Quando acontece? Seguindo o mesmo padrão híbrido das falas, o figurino parece compor diferentes tempos e espaços: o dr. Frankenstein (o ator Colin Clive), por exemplo, usa costumes e gravatas do século XX (Figura 2); sua noiva Elizabeth (Valerie Hobson) porta maquiagem, penteados e tailleurs pós-Chanel já bastante populares nos grandes centros urbanos euro-ocidentais dos anos 1930. São elementos de estilo que se afastam da diegese da cena de abertura (1816), e que remetem ao tempo de realização do filme propriamente dito (1935). É uma articulação cronotópica que pode ter passado despercebida por público e crítica, mas que pode ser incorporada na medida em que recebemos aquilo que a personagem-autora Mary Shelley relata como "nosso" momento presente: 1935, assim, seria o futuro de 1816. 


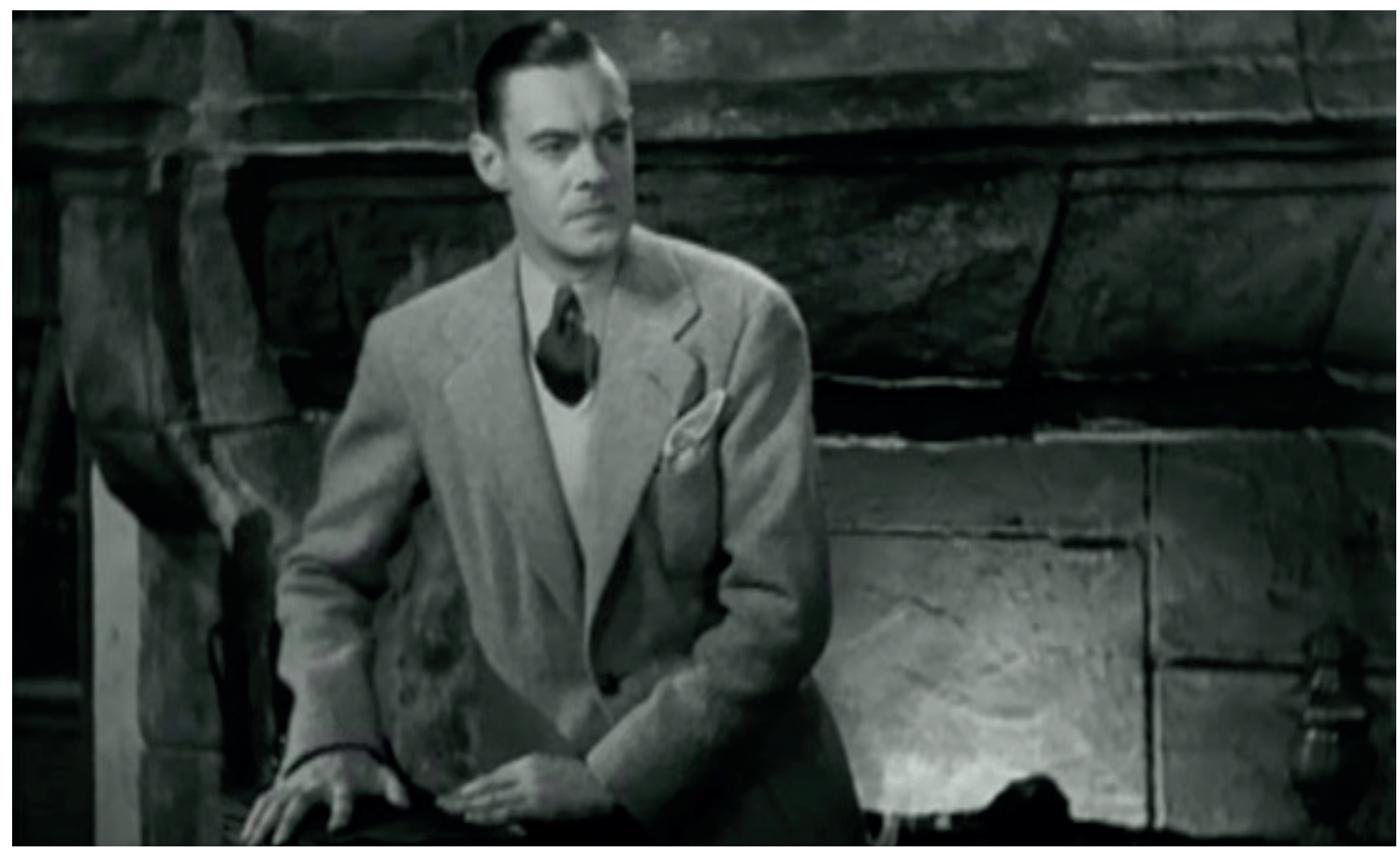

Figura 2

Em outro momento de discrepância temporal Elizabeth e Frankenstein falam por um telefone (vale ressaltar, sem fio), objeto ainda não concebido em 1816. Entretanto, o vislumbre mais radical e grotesco desse futuro talvez esteja na cena em que o dr. Pretorius (Ernest Thesiger), o sinistro ex-professor de Frankenstein, faz uma demonstração dos resultados de suas experiências com clones aprisionados em garrafas. (Figura 3)

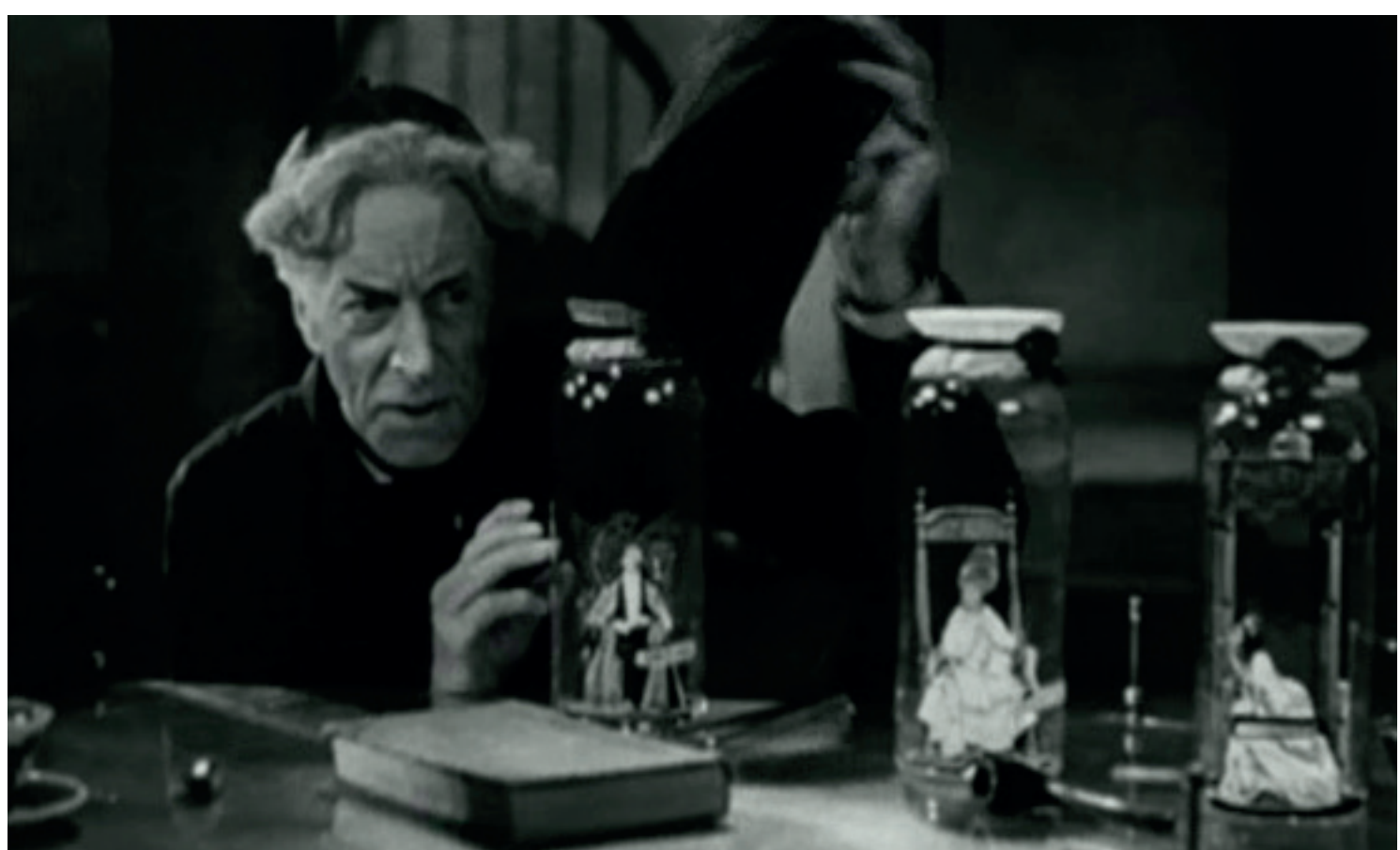

Figura 3 
Seus frascos guardam: uma rainha e um rei (que, pelo figurino, datam do século XVI); um bispo; uma sereia (feita a partir de algas marinhas); uma bailarina (que, monotonamente, dança sempre para a mesma canção de Mendelssohn); um demônio de fraque (que, como Pretorius indica, foi moldado segundo suas próprias feições) (Figura 4).

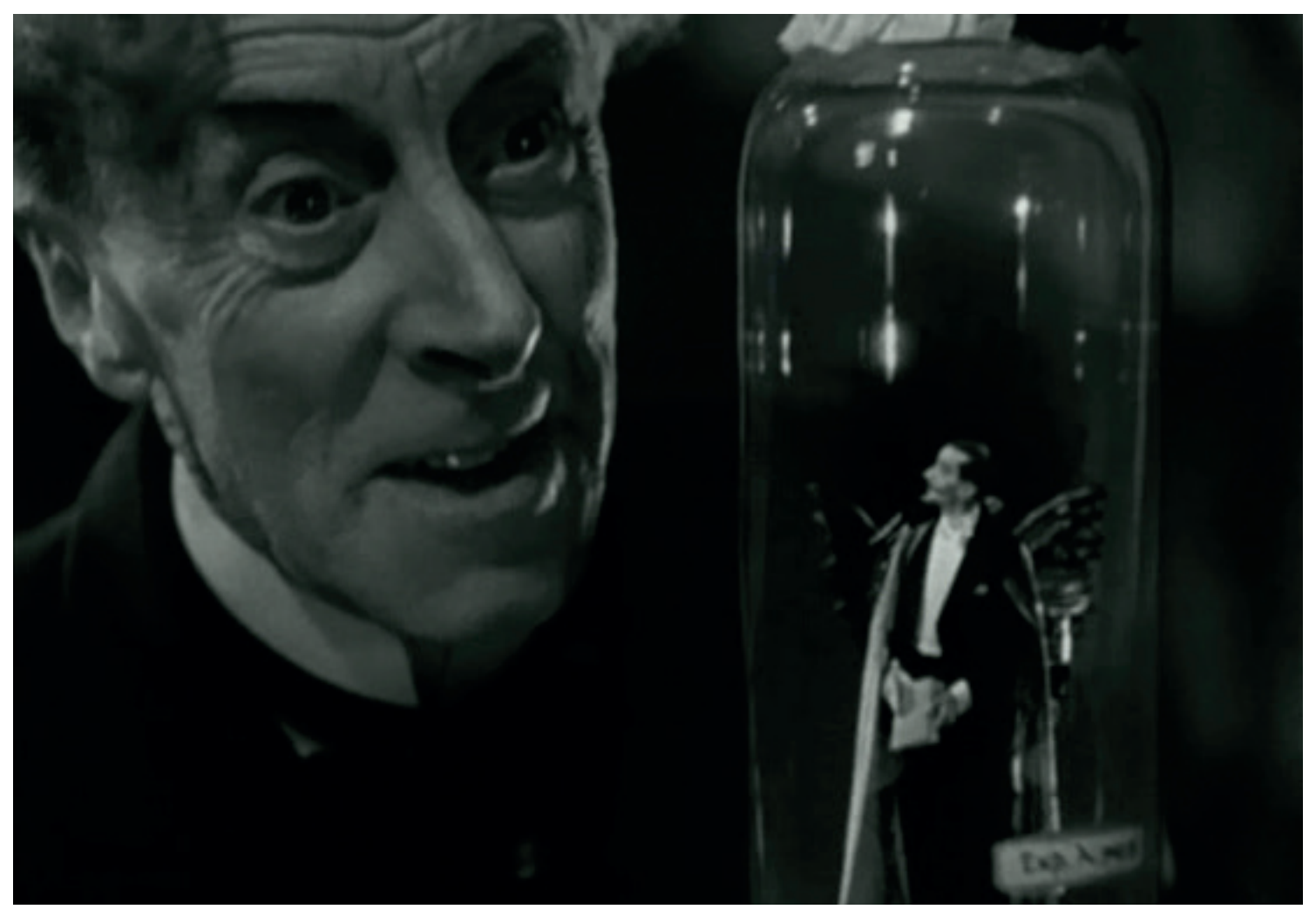

Figura 4

Desse modo, tanto a presença do telefone quanto das experiências genéticas servem para revelar que, na perspectiva da espectatorialidade contemporânea, esse futuro já é nosso passado, estendendo um arco espaço-temporal do passado distante (1816), tocando o passado recente (1935) e nos alcançando no presente (201...). Nessa perspectiva, A noiva de Frankenstein se mostra como um filme de terror com elementos de ficção-científica, agregando partes a um todo difícil de encaixar num só gênero narrativo.

É também Pretorius que vem confundir ainda mais as possíveis cronologias diegéticas de A noiva de Frankenstein: ao invadir uma cripta em busca de um esqueleto que sirva para compor a noiva, um dos assistentes de Pretorius lê a inscrição do túmulo: "Morreu em 1899, Madeline Ernestine, querida filha de..." A noiva, portanto, é composta de partes do corpo de uma jovem falecida em 1899. 


\section{A noiva transtemporal}

As cenas finais de $A$ noiva de Frankenstein compõem as imagens que tornariam o filme célebre. No laboratório em que trabalham Frankenstein e Pretorius a diegese se confunde ainda mais. O laboratório é cheio de aparatos de complexa tecnologia e oculto numa enorme torre de pedra. Num misto de arquitetura medieval e equipamento futurista, o laboratório traz ressonâncias de outro filme de grande repercussão, realizado cerca de dez anos antes: Metropolis, em que Fritz Lang e Thea von Harbou estabelecem articulações cronotópicas entre a Idade Média (como atestam os cenários da catedral e da casa de Rothwanger, o cientista), uma urbe futurista (muito semelhante às metrópoles norte-americanas contemporâneas do filme), e um laboratório em que se criam humanoides (e que estabeleceria um padrão iconográfico para inúmeros filmes de ficção científica subsequentes). Em que pesem suas diferenças estéticas, culturais e políticas, os dois filmes criam eras imaginárias próprias, ao reunir momentos e espaços distintos para compor suas narrativas.

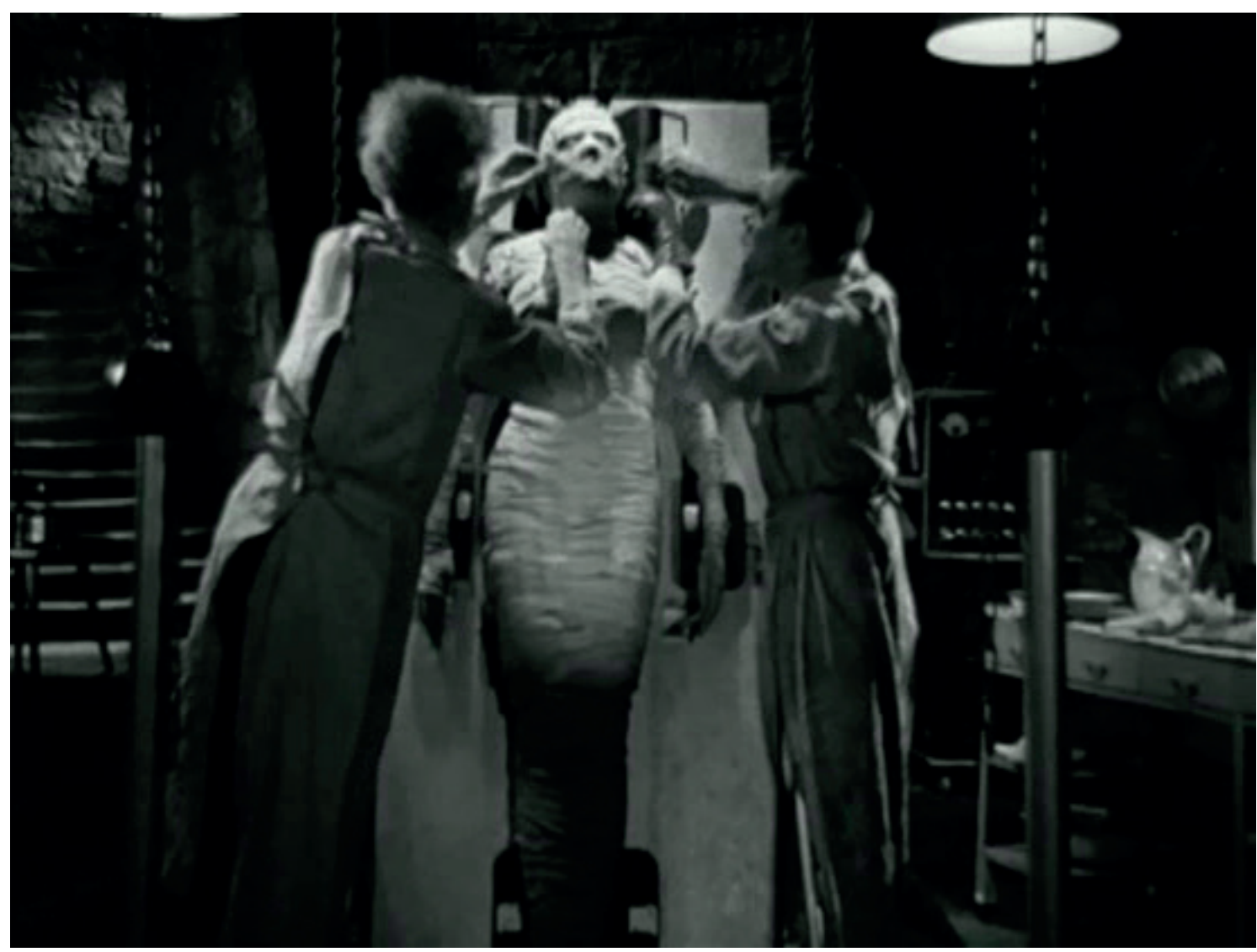

Figura 5 
Trazida à vida, a noiva desper ta e é prontamente assistida por Frankenstein

ano 2 número 4

Temáticas

Livres e Pretorius (Figura 5). Ela se assemelha a uma múmia, envolta em faixas de gaze presas por alfinetes. A cena traz ressonâncias de outros filmes de sucesso na época, como por exemplo, A múmia, dirigido por Karl Freund em 1932 e protagonizado pelo mesmo Boris Karloff que faz o monstro em A noiva de Frankenstein.

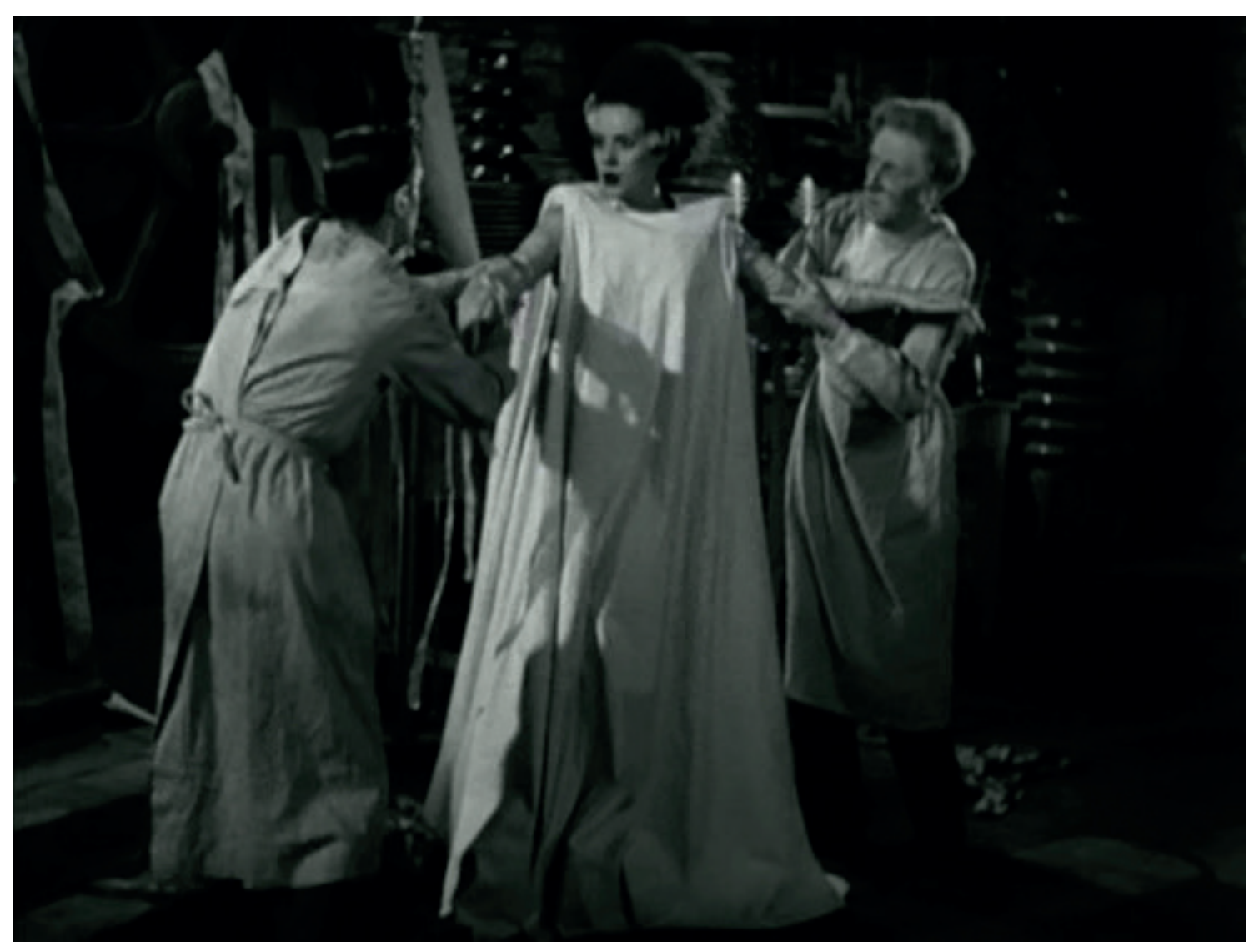

Figura 6

Num cor te em fusão, ela reaparece já devidamente vestida e penteada por seus criadores. Uma vez em pé, a noiva claudica. O quadro evoca a cena de abertura, em que Mary Shelley, ferida pela agulha, é assistida por seu marido e seu amigo (Figura 6). De fácil apreensão, a analogia se torna clara, especialmente quando nos damos conta de que noiva e Mary Shelley são vividas pela mesma atriz, Elsa Lanchester. O filme entabula assim um diálogo lúdico com os espectadores. Nos créditos finais, duas colunas (de personagens e atores) surgem encabeçadas pela frase "A good cast is worth repeating"6, e trazem, mais abaixo, a enigmática 
menção: "The monster's mate...?"7 . A pergunta convida os espectadores a adivinharem o nome omitido de Lanchester.

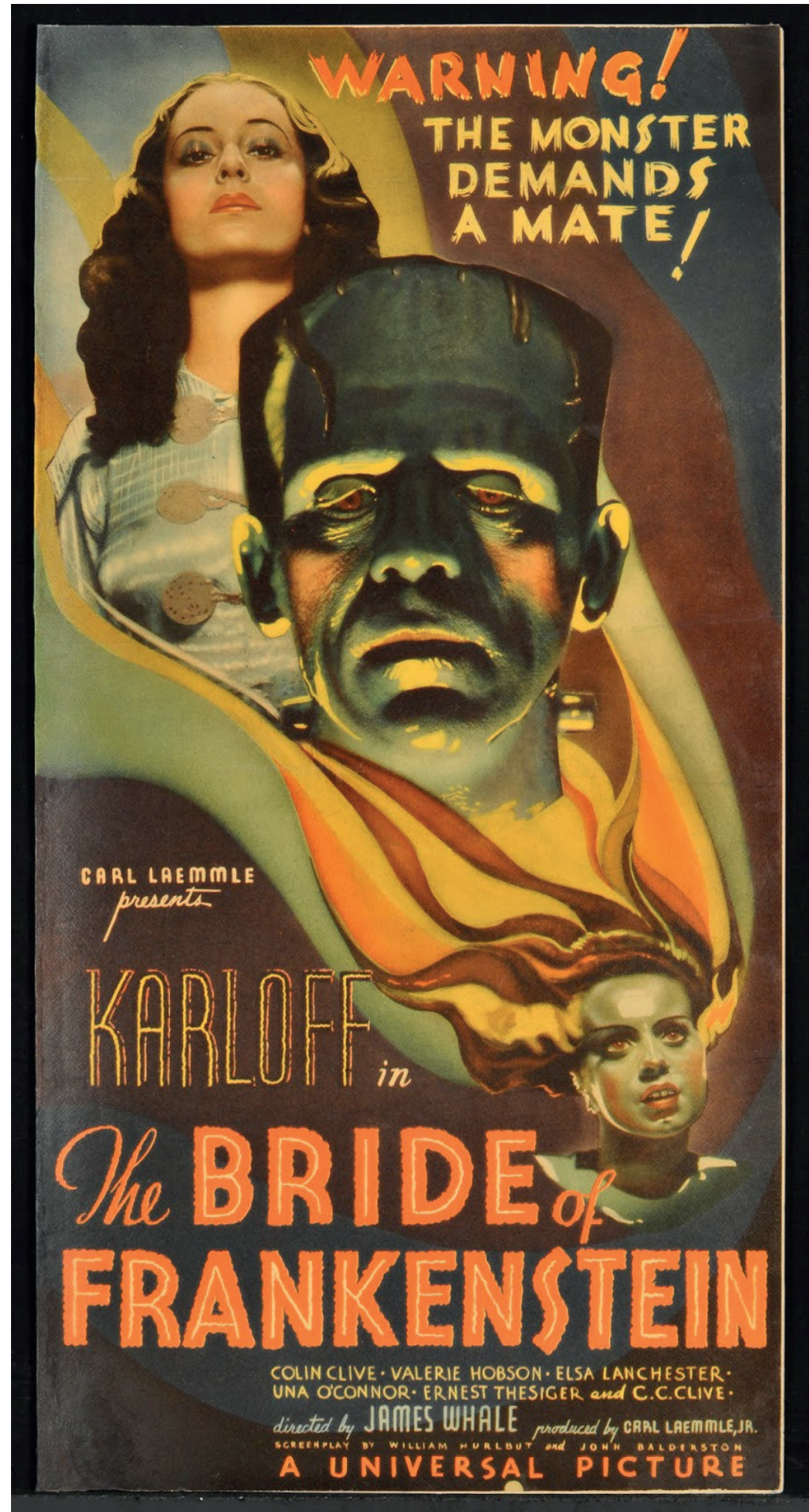

Figura 7

A escolha da atriz sugere uma superposição entre as duas personagens: por um lado Mary, a autora, e por outro a noiva, sua criação. Vale lembrar também 
ano 2 número 4

Temáticas

Livres

que o próprio título do filme abre a possibilidade de outra superposição, na medida em que "noiva" pode significar duas personagens: Elizabeth, a noiva do dr. Frankenstein, e a parceira do monstro, criada para ser sua noiva. ${ }^{8}$ É algo sugerido também pelo cartaz de lançamento do filme, em que Elizabeth e a noiva parecem compor um casulo que contém a cabeça do monstro. (Figura 7) São estratégias narrativas, intra e paratextuais, que funcionam como um jogo de espelhos, em que não apenas são confundidos tempos e espaços, mas também as identidades. De certo modo, A noiva de Frankenstein parece insistir em incertezas: diante da opacidade deste filme, a espectatorialidade, com uma expectativa baseada na suspensão da descrença e na segurança da continuidade, é desestabilizada, invadida por desconfiança e suspeita.

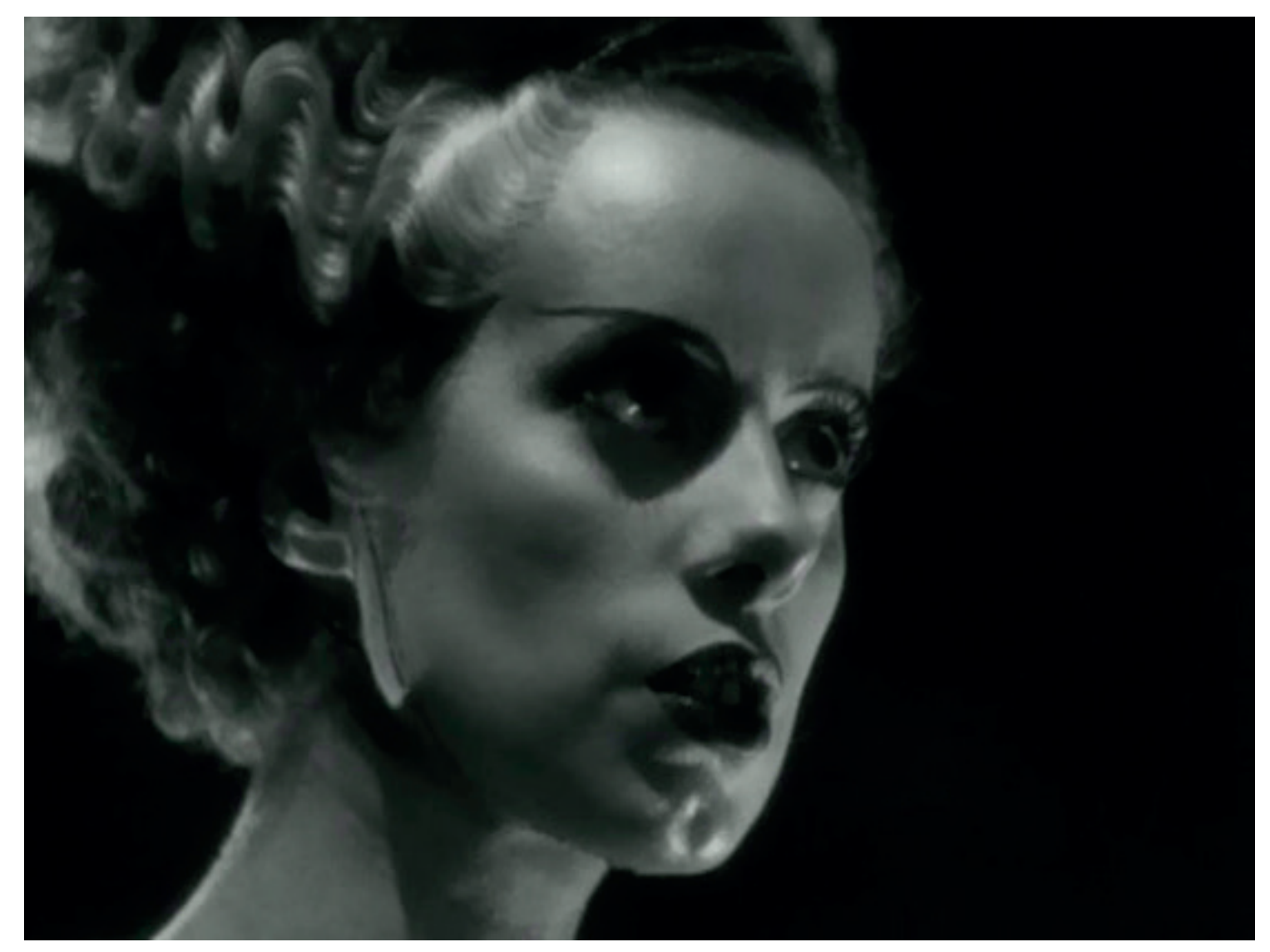

Figura 8

A cena final traz para primeiro plano o trabalho de dois profissionais - cujos nomes não aparecem nos créditos — e que foram responsáveis por detalhes

8. De modo semelhante, costumamos aceitar a operação metonímica que faz de "Frankenstein" o equivalente de "Monstro de Frankenstein", ou seja, o ser criado pelo ousado médico, e não o próprio médico. 
que marcaram a memória que muitos de nós temos do filme: a maquiagem, o penteado e o figurino da noiva. Foram eles Jack Pierce (autor da imagem do Monstro nos dois filmes da série dirigidos por Whale) e Otto Lederer (seu colaborador) que, sob orientação de Whale, criaram o notório penteado em ferro marcel com as eletrizadas mechas brancas da noiva, possivelmente baseado em imagens de Nefertiti. ${ }^{9}$ (Curtis, 1988). Enfaixada ou vestida a noiva se associa, mais uma vez, à antiguidade egípcia (Figura 8).

Em termos cronotópicos, trata-se de mais uma associação que assinala uma era imaginária, em que uma figura do passado remoto se relaciona diretamente com a imagem teleológica que o filme faz de seu presente-futuro. Feita de partes de cadáveres, assim como seu parceiro monstro, a noiva emerge do passado e do além, para projetar-se num futuro transtemporal.

\section{Happy ending?}

Após a explosão da torre-laboratório em que perecem o monstro, a noiva e Pretorius, o filme apresenta um pequeno epílogo: vemos o dr. Frankenstein e sua noiva Elizabeth, que assistem à queda da torre e se abraçam. Ela choraminga e ele a consola, dizendo "Darling, darling...". ${ }^{10}$

Ao invés de retornar a 1816, ou seja, à instância narradora e autoral de Mary Shelley, os espectadores são deixados para sempre nesse presente diegético de 1935, que hoje faz parte irremediável de nosso passado. E se Mary Shelley conduziu uma narrativa de violência e horror até aqui, a aterrorizada Elizabeth a remete de volta ao papel identificado com a mulher frágil e desamparada, prestes a se assustar com uma explosão ou uma simples agulha de bordado,

9. Agradeço ao visagista Valter Sabino (studiosabino@hotmail.com) as preciosas informações sobre a produção do estilo do penteado da Noiva.

10. Talvez tenha sido Whale o criador desse recurso tão freqüente no cinema hollywoodiano: a alavanca onidestruidora (que mais recentemente assumiu a forma de um "botão autodestruidor"), implacavelmente operada pelo Monstro na cena final. É ele quem decide o destino dos personagens, dizendo a Frankenstein e sua noiva: "You live! We belong dead." ("Vocês viver! Nós pertencer aos mortos"). 
ano 2 número 4

Temáticas

Livres carente de um homem que a proteja. Desse modo A noiva de Frankenstein, um filme repleto de ousadia cronotópica, diferença indentitária e liberdade estética, parece se fechar na segurança dos papéis de gênero preconizados pelos valores patriarcais. Mas por outro lado, como sabemos, o monstro e, quem sabe, sua noiva, podem ter sobrevivido à destruição final. 


\section{Referências}

BAKHTIN, Mikhail. The Dialogic Imagination. Austin: University of Texas Press, 1981. Edição brasileira: Questões de Literatura e Estética. São Paulo: Unesp/Hucitec, 1993.

CURTIS, James (1998). James Whale: A New World of Gods and Monsters. Boston, Faber and Faber.

JEHA, Julio. Das origens do mal: a curiosidade em Frankenstein. In Julio Jeha e Lyslei Nascimento. Da fabricação de monstros. Belo Horizonte, Editora da UFMG, 2009.

LIMA, Lezama. Las eras imaginarias. Madrid: Fundamentos, 1971.

XAVIER, Ismail. O discurso cinematográfico: a opacidade e a transparência. Rio: Paz \& Terra, 1977. 